\title{
"Types of employee training, organizational identification, and turnover intention: evidence from Korean employees"
}

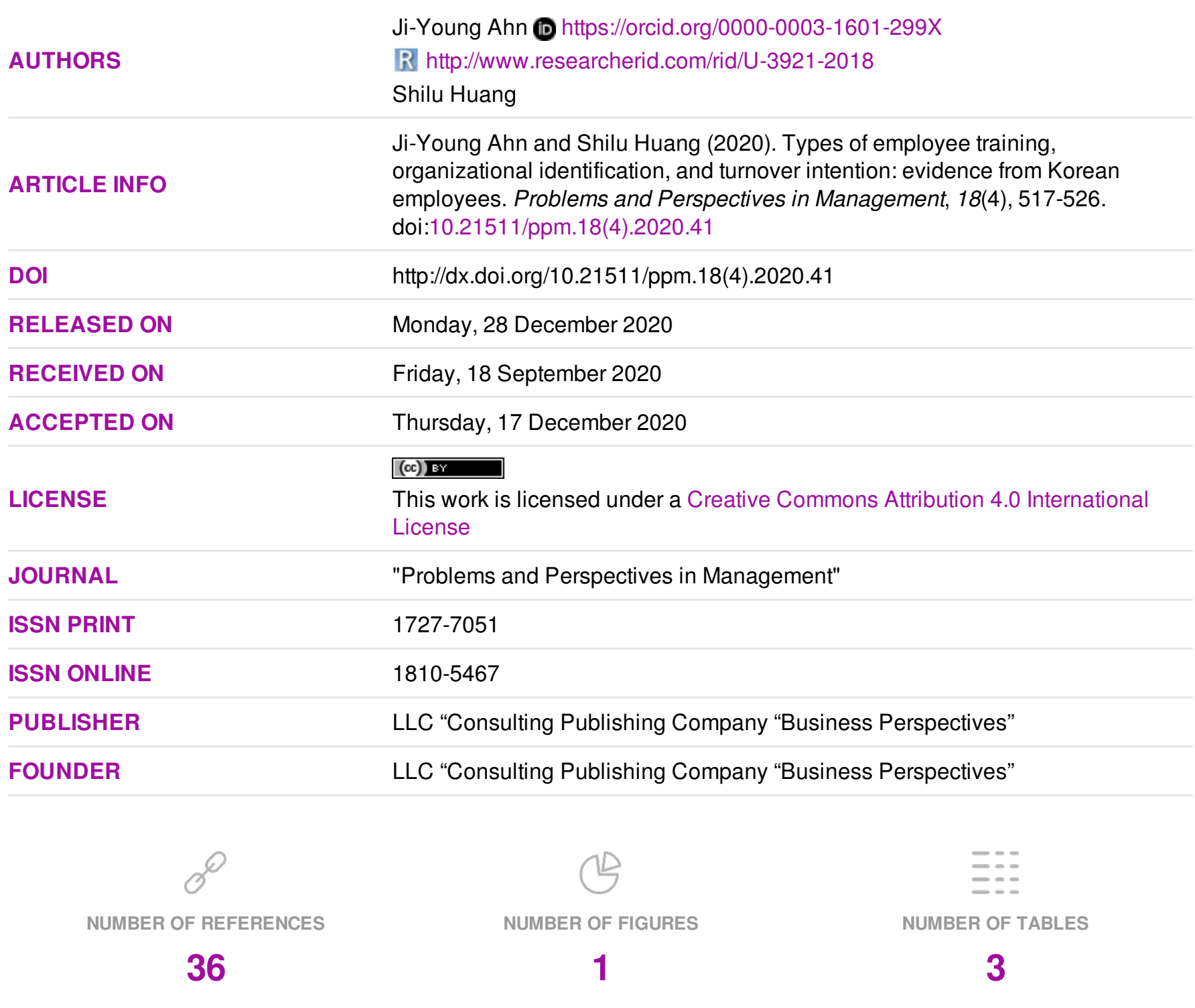

(c) The author(s) 2023. This publication is an open access article. 


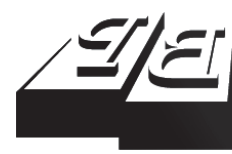

\section{BUSINESS PERSPECTIVES}

LLC "CPC "Business Perspectives" Hryhorii Skovoroda lane, 10, Sumy, 40022, Ukraine www.businessperspectives.org
Received on: $18^{\text {th }}$ of September, 2020 Accepted on: $17^{\text {th }}$ of December, 2020 Published on: $28^{\text {th }}$ of December, 2020

() Ji-Young Ahn, Shilu Huang, 2020

Ji-Young Ahn, Ph.D., Associate Professor in Management, Ewha School of Business, Ewha Womans University, Seoul, Republic of Korea. (Corresponding author)

Shilu Huang, M.Sc., Graduate Student, Ewha School of Business, Ewha Womans University, Seoul, Republic of Korea.

\section{TYPES OF EMPLOYEE TRAINING, ORGANIZATIONAL IDENTIFICATION, AND TURNOVER INTENTION: EVIDENCE FROM KOREAN EMPLOYEES}

\begin{abstract}
Many organizations are willing to increase human capital investment through various employee training programs. This study empirically examines a proposed model that explains the relationship between the different types of employee training, including general and firm-specific training and employee turnover in Korean firms. This study used a survey sample of 10,069 employees in 467 publicly traded firms in South Korea. $78 \%$ of participating companies provided training programs to the employees. This study conducted quantitative cross-sectional regression analyses to test the hypotheses. The study suggests empirical evidence that general training and firm-specific training reduce employee turnover intention. Moreover, the magnitude of firm-specific training on turnover intention is much higher than general training. Furthermore, employee organizational identification has a partial mediating effect on training and turnover intention. However, the study found no substantial evidence of the moderating effect of employees' justice perception of receiving training opportunities. Based on the human capital theory and social exchange perspective, the results indicate that both types of training programs help employee retention, and cultivating employee organizational identification can be critical in the training-turnover process.
\end{abstract}

Keywords

human resource management, training, general training, firm-specific training, organizational identification, turnover intention, human capital theory, social exchange

JEL Classification

M10, M53

\section{INTRODUCTION}

Gaining and maintaining a competitive advantage through human resources is critical to organizations (Barney, 1991). Much evidence shows many firms are willing to increase human resources investment through the various employee training and development programs (Guan \& Frenkel, 2019). Employee training is defined as the training activity planned and targeted in various ways based on the organization's actual work needs (Noe \& Kodwani, 2018). Scholars have confirmed that training could improve economic performance and non-economic performance, including reducing turnover, absence, conflicts, and service quality by improving employees' knowledge, abilities, skills (KSAs, hereafter), and behaviors (Phillips, 2012; Guan \& Frenkel, 2019). Despite its supposed positive effect, organizations can also face the risk of employee turnover when increasing training inputs (Noe \& Kodwani, 2018). It is expected that employees trained in the organization and whose overall quality is improved might leave the company for various reasons, leading to the organization's investment not being returned. Thus, exploring and verifying the relationship between training investment and employee turnover behavior will help the management be better informed on training investment and employee risk aversion. 
There are some unanswered questions to revisit the relationship between a firm's investment in employee training and employee turnover for the following reasons. First, existing research tends to consider training as a holistic concept. Specifically, very few studies have empirically explored the possibility of the differential impact of different training types on employee retention behavior. Training is divided into firm-specific training (specific training, hereafter) and general training (Hashimoto, 1981). Specifically, specific training includes exclusively training related to corporate culture and systems and KSAs in the current organization. In contrast, general training can provide employees with skills and knowledge of universal value and portability to other organizations (Loewenstein \& Spletzer, 1999). Building on prior theoretical predictions, this study argues that general and specific training can have disparate impacts on employees' loyalty or commitment to the organization, leading to a differential effect on turnover behavior.

Furthermore, most research has exclusively emphasized the direct relationship between training and turnover intention. Few have researched the impact process or mechanism through which training can change employee behavior. Specifically, prior research has little paid attention to the role of employees' attitudinal behavior in the process (Ashforth \& Mael, 1998; Dutton et al., 1994). In this vein, this study posits that employees' identification with an organization can intervene between employee training and turnover. The idea behind this is that employee training can help employees recognize the organization's concern for them and their importance to the organization, thereby forming an emotional connection or identity (Pratt, 1998). The stronger the employee's sense of identity, the easier it is for a person to comply with organizational rules and culture, thereby motivating individuals to accomplish goals and remain with them. Thus, it is expected that employees' organizational identification can serve as an intermediate variable to regulate the relationship between training and turnover intention. Additionally, this study explores the possibility that justice perception in receiving training opportunities as potential moderators can strengthen the relationship between training and turnover intention.

\section{LITERATURE REVIEW}

Much debate on the relationship between employee training and turnover has been exclusively focused on the impact of general training on turnover (e.g., Guan \& Frenkel, 2019). However, studies on employee training-turnover relationship are mixed at best. For instance, proponents of human capital theory posit that general training can increase employees' value to other companies, thereby increasing the risk of turnover (Milgrom \& Roberts, 1993). This view is built upon the premise of a perfect labor market, indicating that information is symmetrical (Becker, 2009). Notably, employees' ability to improve through general training can be adequately understood by other organizations, and the employer bears the cost of general training. Thus, when turnover risk is highly expected, firms might reduce general training (Milgrom \& Roberts, 1993). However, the studies later argued that due to asymmetric information between current and prospective employers in a labor market, the skills provided by general training could also be specific skills, which can limit the labor mobility across different employers (Forrier \&
Sels, 2003). Thus, firms are willing to share general training costs and increase their human capital investment, consistent with Acemoglu and Pischke's (1998) seminal work. Taken together, the impact of general training on turnover intention is ambiguous that calls for empirical investigation.

In contrast, views on the impact of specific training on employee retention have been mainly consistent across various contexts, suggesting that specific training can reduce turnover behavior. This is because the skills employees have acquired through specific training are only applicable to the organization, which can, in turn, lead employees to be more restricted in the job search process, thereby decreasing turnover (De Winne \& Sels, 2010). Furthermore, according to Acemoglu and Pischke (1998), the current information asymmetry between a current employer and other companies about workers' training levels will limit labor market mobility. Under this labor market, employees' universal skills are likely to be incorrectly assessed by external organizations and recognized by the organization (Katz \& Ziderman, 1990). 
Several studies have recently connected the idea of employee training to employees' sense of identification with the organization (e.g., Eisenbeiss \& Otten, 2008). From the social identification theoretical perspective, employees tend to personalize and form a shared sense of destiny with the organization, reducing negative behaviors such as turnover (Hogg \& Turner, 1987; Hogg \& Terry, 2000). Empirical evidence confirms the argument. For example, the experiment by Lincoln and Kalleberg (1996) in Japan finds that training within organizations can increase identity recognition and enhance attachment. Besides, Wang et al. (2008) took organizational identity as a part of organizational culture and provided strong evidence of a positive relationship between organizational culture and human capital investment.

An important question naturally arises as to how different training types can affect employee turnover, respectively, in the training-turnover process. Based on social identity theory, it is expected that training provided organization is more likely to give employees the signal of care (Hogg \& Turner, 1987; Hogg \& Terry, 2000). Specifically, general training can provide employees with skills and knowledge of universal value and portability to other organizations. When employees acquire such knowledge and skills through general training, employees also increase employees' value not only for organizations but also for other organizations outside (Milgrom \& Roberts, 1993). Similarly, the research reviewed by $\mathrm{Wu}$ et al. (2006) shows that higher levels of organizational general human capital investments are associated with reciprocity or social exchange relationships that can create a sense of obligation among employees. Thus, it is expected that the general skills can help employees increase their sense of identification with the organization to exchange training opportunities and remain with the organization.

Specific training can also deepen the organization's understanding by employees who participate in the training, leading them to quickly identify with the organization (Noe \& Kodwani, 2018). When employees find that KSAs acquired through firm-specific training can be fully applied to their current work, the human capital acquisition is more likely to be embedded in the current job or organization (Barth, 1997; Lazear, 2009). Therefore, it is predict- ed that specific training reduces turnover intention through an increased perception of employees' organizational identification.

There is still a remaining question to ask how companies set up a portfolio of various training programs, given the supposed effects on turnover. The above question is important because firms differ widely in their ability to manage the effect of different training types. Put differently, the differences in a mix or composition of specific and general training can cause the differences in turnover indication. Becker (2009) initially argues that general training can increase employee turnover due to increased employability, while specific training reduces separation risk. Moreover, the imperfect market theory posits that information asymmetry can reduce the risk of employee turnover caused by general training. Therefore, the organization is less disincentivized to invest in general training (Katz \& Ziderman, 1990; Lazear, 2009).

As discussed above, this study suggested that specific training on turnover intention is more significant than general training. Part of the reasons might be that employees often participate in the specific training program with paid fees (Autor, 2001). Most of the training program targets filling the current deficit in skills and knowledge when employees perform the current job (Noe \& Kodwani, 2018). When the proportion of specific training to general training is higher, it sends the signal to employees the importance of firm-specific human capital over general human capital. Therefore, employees are more likely to commit to the current organization by accumulating coworker complementarity or coworker-specific social capital (Hayes et al., 2006). Therefore, employees who receive a high percentage of specific training would encounter a significant social capital loss when individuals decided to leave (Hayes et al., 2006). Furthermore, the proprietary nature of the skills provided by specific training also increases the difficulty of employee mobility (Milgrom \& Roberts, 1993; Lazear, 2009). Overall, with greater importance of specific training to general training, employees tend to have a strong sense of organizational identity, reducing turnover intention.

This study argues that employees' training opportunities are also essential internal resources in the organization. Therefore, the unfair distribution of 
training opportunities will also affect the organizational identity of employees. From the organization justice perspective, distributive justice, which is defined by the perceived fairness of workplace outcomes and resource allocation, is vital for affecting organizational identification (Lipponen, Olkkonen, \& Moilanen, 2004). Previous research has suggested that organizational justice can help employees receive psychological recognition and trust (Wang et al., 2008). Moreover, from the equity theory view, employees tend to compare themselves to others (Adams, 1965). Those involved in employee training may be compared to under (over) investment or lack of other comparable organizations' training opportunities. When the organization's differences in general training opportunities are minimal, employees experience a 'feeling of equity' or organizational justice, thereby enhancing organizational identification. Thus, it is expected that perceived fairness by receiving training opportunities strengthens organizational identification, leading to decreased turnover intention. Similarly, the rationale also applies to specific training. Suppose the opportunity for specific training is unfair, or an employee fails to receive the specific training available to the organization. In that case, the employee will generate dissatisfaction and question the organization's system and culture, thus reducing organizational identification.

\section{AIMS AND HYPOTHESES}

The study aims to empirically examine the relationship between employee training and turnover intention, particularly the differential effects of employee training on turnover intention using the employ-

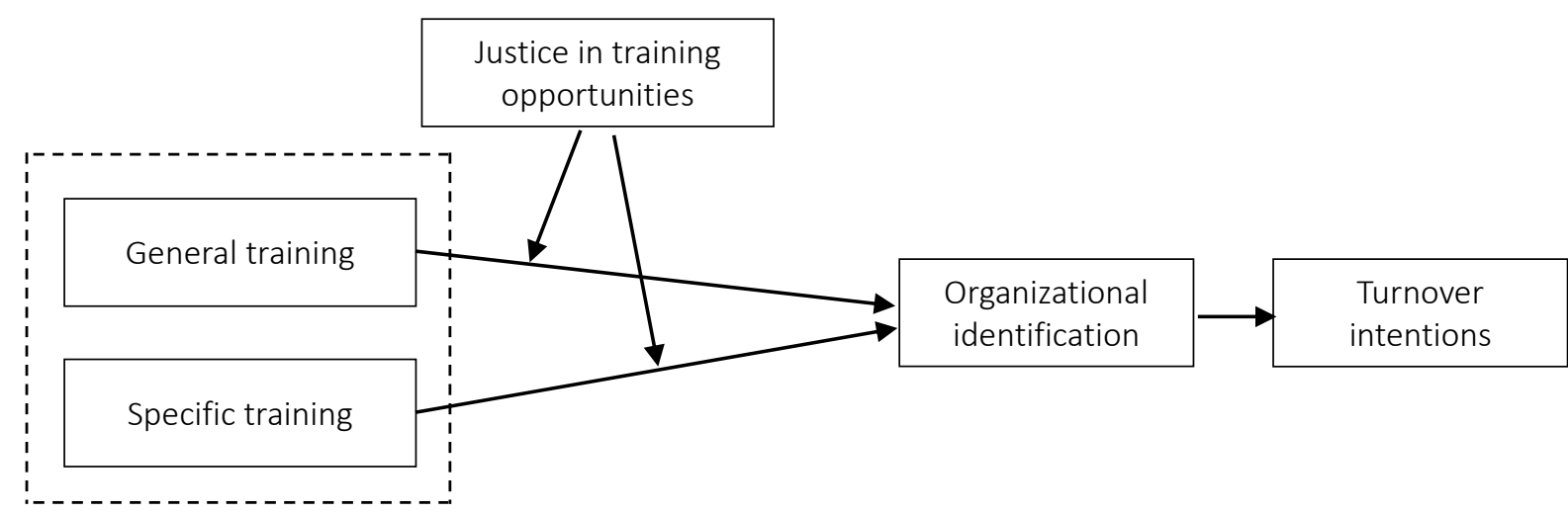

ee-employer survey data provided by the Korean government-sponsored research institution in 2015. This study explored the possibility of a proposed model that explains employee identification to an organization that can mediate the effect of training on employee turnover. Additionally, the study also extends the notion of employees' justice perception to receiving training opportunities to examine whether the perception moderates the relationship between employee training and organizational identification.

The research hypotheses are as follows:

H1: General training is related to employee turnover intention

H2: Specific training is negatively related to employee turnover intention.

H3: Organizational identification mediates the relationship between employee training and turnover intention.

H4: The proportion of specific training to the total training is positively associated with organizational identification.

H5: The perceived justice of receiving training opportunities moderate the relationship between training and organizational identification.

\section{METHODS}

\subsection{Research model}

Figure 1. Research model 


\subsection{Sample}

The study sample was constructed from the Human Capital Corporate Panel (HCCP), a government-sponsored employee-employer survey in 2015 (KRIVET, 2016). In this study, the analysis unit uses a 'workers survey' covering 10,069 employees across 467 publicly traded companies in Korea. Among 467 companies that participated in the survey, 349 were manufacturing companies, 32 were financial, and 82 were non-financial services. A large majority of participating companies $(78.2 \%)$ provide training programs to their employees. The data on training information and employee attitudes and behaviors, as recorded in 2015, are included.

\subsection{Measures}

\subsubsection{General training}

This study used Loewenstein and Spletzer's (1998) scale to assess the scope and variety of general training use. The scale includes the following training programs: collective internal training, collective external training, internet learning, and training by correspondence. Respondents indicated the degree with which employees participated in the training program using a categorical variable, indicating either 0 (not participate) to 1 (participate). Then the variable is added up each response to generate the scale. It is indicated that Cronbach's alpha was .606.

\subsubsection{Specific training}

This study also utilized Loewenstein and Spletzer's (1998) typology and scale to assess the scope and variety of specific training that includes the following programs: career development planning, mentoring or coaching, study group, on-the-job training, and job rotation. Respondents indicated the degree with which employees participated in the training program using a categorical variable, indicating either 0 (not participate) to 1 (participate). Then the study adds up each response to generate the scale. Cronbach's alpha was noted at .683 .

\subsubsection{Organizational identification}

The variable was measured by a three-item scale based on Hogg and Terry (2000). It states, "My company's issues feel like my own," "It pays to be loyal to this company," and "My company's management is trustworthy and reliable in all respects." to capture the degree of organizational identification by the employees. Using a 5-point scale, from 1 to 5 , meaning "totally disagree" and "fully agree," respectively, the respondents indicated the degree to which employees feel identified with their current organization. A higher score indicates a greater organizational identification as experienced by the employee. The Cronbach's alpha of 0.692 was reached.

\subsubsection{Turnover intention}

Turnover intention was assessed by asking survey participants: "I will consider transferring to another company that offers better condition" (Tett \& Meyer, 1993). Employees rated these items on a scale ranging from 1 "totally disagree" to 5 "totally agree."

\subsubsection{Perceived justice in receiving training opportunities}

The variable was measured by a single-item scale based on Paterson et al. (2002), stating "My company provides equal training opportunities to all employees," Employees rated these items ranging from 1 "totally disagree" to 5 "fully agree."

\subsubsection{Control variables}

This study controlled for two demographic variables in the study: tenure, gender, and age. Tenure is measured with years of staying with an organization. It is noted that the longer the employees stay in the organization, the lower the turnover intention (Ahn \& Chaoyu, 2019). Also, younger employees or male workers may have a higher turnover intention than older ones or female workers (Pitts et al., 2011).

\section{RESULTS}

The descriptive statistics of the variables are presented in Table 1. General training and specific training are independent variables and are negatively related to turnover intention. The average turnover intention of the sample is 2.79 out of 5 . 
Table 1. Descriptive statistics and correlations

\begin{tabular}{|c|c|c|c|c|c|c|c|c|c|}
\hline Variables & Mean & S.D. & 1 & 2 & 3 & 4 & 5 & 6 & 7 \\
\hline 1. Specific training & .85 & 1.21 & & & & & & & \\
\hline 2. General training & 1.65 & 1.24 & $.39 * *$ & & & & & & \\
\hline $\begin{array}{l}\text { 3. Organizational } \\
\text { identification }\end{array}$ & 10.41 & 2.24 & $.20 * *$ & $.23^{* *}$ & & & & & \\
\hline 4. Turnover & 2.79 & 1.19 & $-.11 * *$ & $-.09 * *$ & $-.23^{* *}$ & & & & \\
\hline 5. Perceived justice & 3.22 & 1.02 & $.24^{* *}$ & $.37 * *$ & $.39 * *$ & $-.17 * *$ & & & \\
\hline 6. Ratio of specific training & .27 & .29 & $.74 * *$ & $-.72 * *$ & $.73 * *$ & $-.05 * *$ & $.03^{* *}$ & & \\
\hline 7. Tenure & 10.26 & 35.68 & $-.09 * *$ & $-.09 * *$ & $-.12 * *$ & $.07 * *$ & $-.03 * *$ & $-.65 * *$ & \\
\hline 8. Age & 39.95 & 10.62 & $.022^{* *}$ & $.039 * *$ & $-.055^{* *}$ & $.177^{* *}$ & $.077^{* *}$ & $.03 *$ & $.13^{* *}$ \\
\hline
\end{tabular}

Note: $n=10,069$. The values in the table are standardized regression coefficients. ${ }^{*} p<0.05 ;{ }^{* *} p<0.01 ; * * *<0.001$.

The mean of the proportion of specific training to total training is 0.27 . It is also indicated that receiving training opportunities is negatively related to turnover intention and positively correlates with organizational identification.

Table 2 shows the results of regression analyses of turnover intention. The highest value of the variance inflation factor (VIF) from all models was 5.73, noting no multicollinearity in the study sample (Aiken, West, \& Reno, 1991). This study tested a mediation hypothesis using the Sobel test (Koopman et al., 2015 ) to test the mediating effect of organizational identification between different training program types and turnover intention. Model 1 in Table 2 included only the control variables and two main independent variables. It finds that male or older employees are negatively related to turnover intention.

Table 2. Results of regression analysis of turnover intention (mediation model)

\begin{tabular}{|c|c|c|c|c|}
\hline \multirow{2}{*}{ Variables } & \multicolumn{4}{|c|}{$\begin{array}{l}\text { Dependent variable: turnover } \\
\text { intention }\end{array}$} \\
\hline & $\begin{array}{c}\text { Model } \\
1\end{array}$ & $\begin{array}{c}\text { Model } \\
2\end{array}$ & $\begin{array}{c}\text { Model } \\
3\end{array}$ & $\begin{array}{c}\text { Model } \\
4\end{array}$ \\
\hline \multicolumn{5}{|c|}{ (Constant) } \\
\hline Age & $-.020 * *$ & $-.019 * *$ & $-.020 * *$ & $-.019 * *$ \\
\hline Gender & $-.094 * *$ & $-.043 * *$ & $-.091^{* *}$ & -.040 \\
\hline Tenure & .000 & .003 & .002 & .005 \\
\hline Specific training & $-.082 * * *$ & $-.057 * * *$ & & \\
\hline General training & $-.065^{* * *}$ & $-.033^{* * *}$ & & $-.097 * * *$ \\
\hline $\begin{array}{l}\text { Organizational } \\
\text { identification }\end{array}$ & & $-.105^{* * *}$ & & \\
\hline $\begin{array}{l}\text { The proportion of } \\
\text { specific training to } \\
\text { total training }\end{array}$ & & & $-.217^{* * *}$ & $-.167^{* * *}$ \\
\hline Sobel test statistics & & $11.797 * * *$ & & $-5.974 * *$ \\
\hline F & 130.561 & 188.187 & 106.747 & 153.027 \\
\hline$R^{2}$ & 049 & .086 & .037 & .068 \\
\hline$\Delta R$ & & $.078^{* *}$ & & \\
\hline
\end{tabular}

Note: $n=10,069$. The values in the table are standardized regression coefficients. ${ }^{*} p<0.05 ;{ }^{* *} p<0.01 ;{ }^{* *} p<0.001$.
As presented in model 2 in Table 2, specific training and general training are associated with turnover intention, respectively $(\beta=-0.082, \beta=-0.065$, $p<0.001)$. It shows that specific training on turnover intention is more significant than general training when controlled. This study maintains that these findings support Hypothesis 1 and Hypothesis 2. Moreover, model 2 yields more explanatory power than was indicated in model 1. This study also used model 2 to test the mediation hypothesis. The regression coefficient of organizational identification is negative $(\beta=-0.105$, $p<0.01$ ), which supports that organizational identification is negatively related to turnover intention.

The results also support the mediation effect of organizational identification in the types of training-turnover intention link. In model 2, compared with model 1, after including organizational identification in the empirical model, the coefficients of general training and specific training are decreased up to $(\beta=-0.033, \beta=-0.057, p<0.001)$, and coefficients are still significant. Moreover, the mediation model has passed the Sobel test, indicating the test statistics of $11.796(p<0.001)$. Likewise, compared with Model 3, the coefficients of the proportion of specific training to total training is reduced from -0.217 to $-0.167(p<0.001)$. The findings indicate that organizational identification mediates the relationship between training and turnover intention links, supporting Hypothesis 3. The study also tested the relative importance of specific training on turnover intention, as noted by Hypothesis 4. This study calculated the proportion of specific training to total training and analyzed its relation to turnover intention. The results presented in models 3 and 4 of Table 2 suggest that the proportion of specific training is negatively associated with turnover in- 
tention, implying that a firm's high investment in specific training relative to general training may reduce the employee's turnover intention.

Lastly, this study examined the moderating effect of perceived justice in receiving training opportunities in the relationship between training and organizational identification. Table 3 shows the results of regression analyses on organizational identification. It finds that perceived justice in receiving training opportunities has an impact on organizational identification. However, it appears that it does not play a moderating role in linking training types to organizational identification. Hypothesis 5 suggests that justice in training opportunities moderate the relationship between training and organizational identification. Model 2 of Table 2 shows that the interaction term's regression coefficient is not statistically significant $(\beta=-0.010)$. There is not enough evidence supporting the hypothesis that an employee's perceived justice in receiving training opportunities will moderate the positive relationship between the employee's use of each type of training programs on employee identification.

Table 3. Results of regression analysis of organizational identification (moderating model)

\begin{tabular}{|c|c|c|}
\hline \multirow[t]{2}{*}{ Variables } & \multicolumn{2}{|c|}{$\begin{array}{c}\text { Dependent variable: } \\
\text { organizational identification }\end{array}$} \\
\hline & Model 1 & Model 2 \\
\hline \multicolumn{3}{|c|}{ (Constant) } \\
\hline Age & $-.016^{* * *}$ & $-.016^{* * *}$ \\
\hline Gender & $-.497 * * *$ & $-.496 * * *$ \\
\hline Tenure & .000 & .003 \\
\hline Specific training & $.159 * *$ & $.196 * *$ \\
\hline General training & $.106 * *$ & $.138^{* *}$ \\
\hline $\begin{array}{l}\text { Perceived justice in } \\
\text { receiving training } \\
\text { opportunities }\end{array}$ & $.762 * *$ & $.784^{* *}$ \\
\hline $\begin{array}{l}\text { Training x perceived } \\
\text { justice in receiving } \\
\text { training opportunities }\end{array}$ & & -0.010 \\
\hline $\mathrm{F}$ & 441.918 & 445.682 \\
\hline$\Delta F$ & & $3.764 *$ \\
\hline$R^{2}$ & 0.10 & 0.181 \\
\hline$\Delta R$ & & $0.081^{* *}$ \\
\hline
\end{tabular}

Note: $n=10,069$. The values in the table are standardized regression coefficients. ${ }^{*} p<0.05 ; * * p<0.01 ; * * * p<0.001$.

\section{DISCUSSION}

The purpose of this study was to revisit the relationship between training and employee turnover intention using a sample of individual employees based in Korean publicly traded firms. The study also attempted to provide a more comprehensive model of the training-turnover process by exploring the potential mediating and moderating factors. The study's basic premise is that general training can promote employee mobility across organizations, while specific training reduces employee turnover due to accumulated firm-specific human capital (Milgrom \& Roberts, 1993; Lazear, 2009). It is worth noting that some organizations are still reluctant to increase their investment in general training in practice.

The results indicate that both general training and specific training can reduce employee turnover intention (Hypotheses 1 and 2). Specifically, building on the social exchange perspective, the firm's investment in general training can also provide employees with the opportunity to improve their general skills. Employees tend to recognize such an opportunity as 'reciprocity' or social exchange for their work, thereby increasing their sense of identification with the organization. This mechanism was confirmed by the mediating factor of organizational identification (Hypothesis 3). This study's empirical evidence shows that employee organizational identification has a partial mediating effect of training on turnover intention. The finding is generally consistent with a prior study indicating the mediating process, which may affect the turnover intention based on a firm's investment in training and development (Forrier \& Sels, 2003). The results also show that a higher proportion of specific training to total training is associated with the more substantial training effect on reducing turnover intention as predicted by Hypothesis 4. The results imply that organizations can adjust the proportion of general training and special training to achieve the maximum results. Overall, the findings indicate that both types of training programs can play positive roles in employee retention, and cultivating employee organizational identification can be critical in the training-turnover process.

Moreover, there is no substantial evidence that perceived employee justice in receiving training opportunities can moderate the strength of the relationship between training and employ- 
ee identification (Hypothesis 5). This study presumed that perceived justice in receiving training opportunities is a significant factor in magnifying employee training's positive aspect of employee outcomes as purported by Topcic et al. (2016). One possibility for the absence of effect might be that employee perceived justice can also be a source of organizational commitment concerning the idea that perceived justice is a complimentary resource embedded with organizational commitment in strengthening the training-identification link (Lipponen, Olkkonen, \& Moilanen, 2004). Therefore, it seemed plausible that perceived justice has little additional or marginal effect on organizational identification, consistent with Dysvik and Kuvaas (2008).

\section{CONCLUSION}

The study aimed to revisit the relationship between employee training and turnover intention. Specifically, this study empirically examined the differential effects of employee training on turnover intention using the Korean government-sponsored research institution's employee-employer survey data in 2015. The findings indicate that general training and firm-specific training reduce employee turnover intention. Furthermore, employee organizational identification partially mediates the relationship between training and turnover intention.

This research has the following theoretical and empirical contributions. First, this study examines the potential process variables in explaining the impact of the employee training-turnover relationship. Specifically, the existing literature on the effects of training on turnover has been characterized by mixed results at best. Besides, most research has exclusively emphasized the direct relationship between training and turnover intention. Thus, this study has primarily explored the possibility that employees' identification of an organization can intervene between employee training and turnover intention. The results confirm that organizational identification mediates employee training and turnover intention based on the social exchange perspective. Secondly, this study contributes to empirically examining that the different types of employee training have varying effects on employee turnover. Building on human capital theory, training is divided into specific training and general training. This study predicts that general and specific training can have disparate impacts on employees' loyalty or commitment to the organization, leading to a differential effect on turnover behavior. This study also implies that differences in training composition or a mix of general vs. firm-specific training will lead to employee turnover differences across organizations. The results show that both general and specific training negatively impact turnover intention. Its magnitude is much more extensive for specific training than general training, implying asset specificity in specific training.

\section{AUTHOR CONTRIBUTIONS}

Conceptualization: Ji-Young Ahn, Shilu Huang.

Data curation: Shilu Huang.

Formal analysis: Ji-Young Ahn, Shilu Huang.

Investigation: Shilu Huang.

Methodology: Ji-Young Ahn, Shilu Huang.

Project administration: Ji-Young Ahn.

Supervision: Ji-Young Ahn.

Validation: Ji-Young Ahn.

Writing - original draft: Shilu Huang.

Writing - review \& editing: Ji-Young Ahn. 


\section{REFERENCES}

1. Acemoglu, D., \& Pischke, J. S. (1998). Why do firms train? Theory and evidence. The Quarterly Journal of Economics, 113(1), 79-119. https://doi. org/10.1162/003355398555531

2. Adams, J. S. (1965). Inequity in social exchange. Advances in Experimental Social Psychology, 2, 267-299. https://doi.org/10.1016/ s0065-2601(08)60108-2

3. Ahn, J., \& Chaoyu, W. (2019). Job stress and turnover intention revisited: evidence from Korean firms. Problems and Perspectives in Management, 17(4), 5261. https://doi.org/10.21511/ ppm.17(4).2019.05

4. Aiken, L. S., West, S. G., \& Reno, R. R. (1991). Multiple regression: Testing and interpreting interactions. Sage. https://doi. org/10.2307/2583960

5. Ashforth, B. E., \& Mael, F. A. (1998). Sustaining Valued Identities. Power and Influence in Organizations, 89(11), 89-120. https://doi. org/10.4135/9781483345291.n5

6. Autor, D. H. (2001). Why do temporary help firms provide free general skills training? The Quarterly Journal of Economics, 116(4), 1409-1448. https://doi. org/10.1162/003355301753265615

7. Barney, J. (1991). Firm resources and sustained competitive advantage. Journal of Management, 17(1), 99-120. https://doi. org/10.1177/014920639101700108

8. Barth, E. (1997). Firm-specific seniority and wages. Journal of Labor Economics, 15(3), 495-506. https://doi.org/10.1086/209869

9. Becker, G. S. (2009). Human capital: A theoretical and empirical analysis, with special reference to education. University of Chicago Press. https://doi. org/10.2307/2229541

10. De Winne, S., \& Sels, L. (2010). Interrelationships between human capital, HRM, and innovation in Belgian start-ups aiming at an innovation strategy. The
International Journal of Human

Resource Management, 21(11),

1863-1883. https://doi.org/10.1080 /09585192.2010.505088

11. Dutton, J. E., Dukerich, J. M., \& Harquail, C. V. (1994). Organizational images and member identification. Administrative Science Quarterly, 239-263. https://doi. org/10.2307/2393235

12. Dysvik, A., \& Kuvaas, B. (2008). The relationship between perceived training opportunities, work motivation and employee outcomes. International Journal of Training and Development, 12(3), 138-157. https://doi.org/10.1111/ j.1468-2419.2008.00301.x

13. Eisenbeiss, K. K., \& Otten, S. (2008). When Do Employees Identify? An Analysis of CrossSectional and Longitudinal Predictors of Training Group and Organizational Identification 1. Journal of Applied Social Psychology, 38(8), 2132-2151. https://doi.org/10.1111/j.15591816.2008.00384.x

14. Forrier, A., \& Sels, L. (2003). The concept employability: A complex mosaic. International Journal of Human Resources Development and Management, 3(2), 102124. https://doi.org/10.1504/ ijhrdm.2003.002414

15. Guan, X., \& Frenkel, S. (2019). How perceptions of training impact employee performance. Personnel Review, 48(2). https:// doi.org/10.1108/pr-05-2017-0141

16. Hashimoto, M. (1981). Firmspecific human capital as a shared investment. The American Economic Review, 71(3), 475482. https://doi.org/10.1257/ aer.91.1.348

17. Hayes, R. M., Oyer, P., \& Schaefer, S. (2006). Coworker complementarity and the stability of top-management teams. Journal of Law, Economics, and Organization, 22(1), 184212. https://doi.org/10.2139/ ssrn. 516007
18. Hogg, M. A., \& Terry, D. I. (2000). Social identity and self-categorization processes in organizational contexts. Academy of Management Review, 25(1), 121-140. https://doi.org/10.5465/ amr.2000.2791606

19. Hogg, M. A., \& Turner, J. C. (1987). Intergroup behaviour, self-stereotyping and the salience of social categories. British Journal of Social Psychology, 26(4), 325-340. https://doi. org/10.1111/j.2044-8309.1987. tb00795.x

20. Katz, E., \& Ziderman, A. (1990) Investment in general training: the role of information and labour mobility. The Economic Journal, 100(403), 1147-1158. https://doi. org/10.2307/2233964

21. Koopman, J., Howe, M., Hollenbeck, J. R., \& Sin, H. P. (2015). Small sample mediation testing: Misplaced confidence in bootstrapped confidence intervals. Journal of Applied Psychology, 100(1), 194. https://doi. org/10.1037/a0036635

22. KRIVET. (2016). HCCP User's Guide. Seoul: KRIVET.

23. Lazear, E. P. (2009). Firm-specific human capital: A skill-weights approach. Journal of Political Economy, 117(5), 914-940. https:// doi.org/10.1086/648671

24. Lincoln, J. R., \& Kalleberg, A. L. (1996). Commitment, quits, and work organization in Japanese and US plants. ILR Review, 50(1), 39-59. https://doi. org/10.1177/001979399605000103

25. Lipponen, J., Olkkonen, M. E., \& Moilanen, M. (2004). Perceived procedural justice and employee responses to an organizational merger. European Journal of Work and Organizational Psychology, 13(3), 391-413. https://doi. org/10.1080/13594320444000146

26. Loewenstein, M. A., \& Spletzer, J. R. (1999). General and specific training: Evidence and implications. Journal of Human Resources, 710-733. https://doi. org/10.2307/146414 
27. Milgrom, P., \& Roberts, J. (1993). Economics, Organization and Management. Englewood Cliffs. https://doi.org/10.2307/2328903

28. Noe, R. A., \& Kodwani, A. D. (2018). Employee training and development. McGrawHill Education. https://doi. org/10.1002/hrdq.21333

29. Paterson, J. M., Green, A., \& Cary, J. (2002). The measurement of organizational justice in organizational change programs: A reliability, validity and context-sensitivity assessment. Journal of Occupational and Organizational Psychology, 75(4), 393-408. https://doi. org/10.1348/096317902321119565

30. Phillips, J. J. (2012). Return on investment in training and performance improvement programs. Routledge. https://doi. org/10.4324/9780080516257
31. Pitts, D., Marvel, J., \& Fernandez, S. (2011). So hard to say goodbye? Turnover intention among US federal employees. Public Administration Review, 71(5), 751-760. https://doi.org/10.1111/ j.1540-6210.2011.02414.x

32. Pratt, M. G. (1998). Central questions in organizational identification. Identity in organizations, 24(3), 171-207. https://doi. org/10.4135/9781452231495.n6

33. Tett, R. P., \& Meyer, J. P. (1993). Job satisfaction, organizational commitment, turnover intention, and turnover: path analyses based on meta-analytic findings. Personnel Psychology, 46(2), 259-293. https://doi. org/10.1111/j.1744-6570.1993. tb00874.x

34. Topcic, M., Baum, M., \& Kabst, R. (2016). Are high- performance work practices related to individually perceived stress? A job demands-resources perspective. The International Journal of Human Resource Management, 27, 45-66. https:// doi.org/10.1080/09585192.2015.1 043136

35. Wang, I., Shieh, C. J., \& Wang, F. J. (2008). Effect of human capital investment on organizational performance. Social Behavior and Personality: an international journal, 36(8), 1011-1022. https://doi.org/10.2224/ sbp.2008.36.8.1011

36. Wu, J. B., Hom, P. W., Tetrick, L E., Shore, L. M., Jia, L., Li, C., \& Song, L. J. (2006). The norm of reciprocity: Scale development and validation in the Chinese context. Management and Organization Review, 2(3), 377402. https://doi.org/10.1111/ j.1740-8784.2006.00047.x 